\title{
Diagnosis and Management of Paediatric Osteoarticular Infections
}

${ }^{1}$ Kavinda Dayasiri, ${ }^{1}$ Thadchanamoorthy $\boldsymbol{V}$

${ }^{1}$ Base Hospital, Mahaoya, ${ }^{2}$ Faculty of Health care Sciences, Eastern University

\begin{abstract}
Despite advances in treatment and understanding of paediatric osteoarticular infections, management of children with these infections continue to be a challenge due to delayed diagnosis and treatment and emergence of virulent pathogens. The most common paediatric osteoarticular infections include septic arthritis and acute osteomyelitis. The recommended approach is multi-disciplinary management and the mainstay of treatment is parenteral antibiotics. Complications are seen mostly with MRSA and Staphylococcus aureus strains that produce Panton-Valentine leukocidin and in children who have underlying risk factors. Children with septic arthritis and complicated osteomyelitis often need surgical interventions.
\end{abstract}

\section{Key words}

Osteoarticular infections, children, management

\section{Introduction}

Osteoarticular infections in children are an important cause of morbidity as delayed treatment can result in permanent deformity, disability, bone and joint destruction and even death (1). Although most osteoarticular infections occur in previously healthy children, immunodeficiencies, sickle cell anaemia and prematurity are considered risk factors (1). About $20 \%$ of children have a history of preceding accidental trauma (2). Osteoarticular infections in children are most commonly caused by haematogenous spread (3).

Children with osteoarticular infections commonly present with pain (4). Limping and pseudo paralysis are other common presentations. Whilst fever may not be present, presence of fever is more supportive for an osteoarticular infection. Although a child with knee joint septic arthritis can present with high fever, joint swelling and restricted movements, and the diagnosis can easily be suspected, clinical diagnosis is often difficult in children with hip pain (5). This is primarily due to overlapping presenting clinical features of femoral metaphyseal and pelvic osteomyelitis, and hip joint septic arthritis. Spinal infections often present with back pain and impaired ability to sit, bend and stand.

\section{Differential Diagnosis}

There are a number of differential diagnosis for localized joint/ bone pain and limp in children which need to be actively ruled out in whom the diagnosis of septic arthritis and osteomyelitis is not obvious. Reactive arthritis is a common differential diagnosis in non-toxic children who have limp and mild fever and usually follows an upper respiratory tract infection. Fracture and haematoma are differential diagnosis of children with acute onset localised pain with no fever. Haematological malignancies, juvenile idiopathic arthritis and systemic lupus erythematosis have to be considered in children with systemic clinical manifestations. Multifocal and recurrent bone pain in children with low grade persistent fever can be the presentation of chronic recurrent multi-focal osteomyelitis. Recent travel history to a Lyme disease endemic country warrants ruling out Lyme disease related monoarthritis. Congenital syphilis can present with pseudo paralysis of the newborn; however, it is exceedingly rare.

\section{Investigations}

\section{Laboratory investigations}

Full Blood Count (FBC) usually demonstrate neutrophil leukocytosis in osteoarticular infections. Blood film is performed to identify evidence of haematological malignancies. Although both ESR and CRP are elevated in bacterial infections, CRP is more useful for disease activity monitoring since it is more sensitive and decreases faster with definitive treatment. ESR can be very high in haematological malignancies and rheumatological causes of bone/ 
joint pains. Procalcitonin, although not widely available, is highly specific for infections and can help differentiation from inflammatory arthritis (6).

Demonstration of the pathogen from joint aspiration fluids and bone specimens remain the gold standard for diagnosis of septic arthritis and osteomyelitis respectively. Blood cultures should be drawn at the earliest opportunity preferably an adequate volume of at least $2 \mathrm{~mL}$ during a febrile episode and prior to starting antibiotics (8). Staphylococcus aureus is the most common pathogen for both septic arthritis and osteomyelitis outside of neonatal period (7). However, an estimated $30-90 \%$ of young children can have negative cultures $(8,9)$ and Kingella kingae, the other common pathogen for osteoarticular infections have been demonstrated by real-time PCR (Polymerase chain reaction) in these children $(10,11)$. In children who undergo orthopedic interventions all samples of tissue, joint fluid/ pus and bone should be cultured (12).

\section{Radiological investigations}

\section{Plain X-ray}

X-Ray of the affected joint or bones is important to rule out differential diagnosis such as fractures and to look for evidence of bone neoplasms. Supportive radiological features include widened joint space and oedema (septic arthritis), thinning of bone and periosteal elevation (osteomyelitis), and vertebral erosions and reduced intervertebral spaces (spondylodiscitis). However, accuracy of $\mathrm{X}$-ray during early phase of osteomyelitis and spondylodiscitis is limited since characteristic appearance is evident only $2-3$ weeks after onset of disease (13).

\section{Ultrasound}

Ultrasound imaging of affected joint is more sensitive in identifying joint effusions at an early stage of septic arthritis and useful for diagnostic and therapeutic aspiration of the joint. Diagnostic utility of ultrasound in osteomyelitis is limited.

\section{MRI (Magnetic Resonance Imaging)}

MRI is the preferential imaging modality in osteomyelitis and spondylodiscitis and has high sensitivity for early diagnosis (14). However, limiting factors include lack of wide availability and need for sedation in some children.

\section{Radio nucleotide bone scan}

Bone scintigraphy is useful in diagnosis of multifocal osteomyelitis and osteomyelitis of which anatomical extent is less apparent based on clinical examination. Low specificity however, is a limiting factor for its diagnostic accuracy (15).

\section{Treatment}

Osteoarticular infections in children often need a multi-disciplinary approach to management with involvement of paediatrician, orthopedic surgeon, radiologist, microbiologist, emergency care physicians and specialist nurses (16).

\section{Antibiotics}

The mainstay of treatment for osteoarticular infections is empirical use of antibiotics to cover potential pathogens pending definitive diagnosis. (17). The most common pathogens include Staphylococcus aureus and Kingella kingae. However, in young infants less than three months of age, group B streptococcus and Enterobacteria are also known to cause bone and joint infections, therefore a combination intravenous Ceftriaxone/ Cefotaxime and Gentamycin are the preferred first line parenteral therapy.(18) In older children, in whom the likely pathogen is staphylococcus aureus, the infection can be treated with intravenous Flucloxacillin. However, intravenous Ceftriaxone is preferred in children with no microbiological confirmation or the possibility of infection with Kingella kingae is high or confirmed. Consider adding oral clindamycin in children with community acquired methicillin resistant Staphylococcus aureus (MRSA) infections.(19) Staphylococcus aureus and Salmonella are common pathogens in children with sickle cell anaemia and intravenous Ceftriaxone is the antibiotic of first choice.(20) In children with complications such as septic shock, osteoarticular infections should be treated more vigorously and the combination of intravenous Vancomycin and oral Clindamycin is preferred. Mycobacterium tuberculosis and fungal infections should be considered specially in immunecompromised children.(21) Consideration can be given to change over to oral antibiotics 24 48 hours after fever has settled and clinical and biochemical (inflammatory markers) recovery is evident.(22) The total duration of treatment is 2-3 weeks in septic arthritis.(23) and spondylodiscitis; 
however, osteomyelitis needs to be treated for longer duration, usually for 4-6 weeks.

\section{Surgical intreventions}

Children with septic arthritis are likely to need prompt removal of inflammatory fluids from the joint space. The available surgical interventions include arthrotomy, arthroscopy and aspiration. Young infants with hip joint septic arthritis often need arthrotomy.(24) Although $90 \%$ of children with osteomyelitis can be managed without needing surgery but, drainage of pus and debride of necrotic tissues may be required especially in children who do not respond adequately to intravenous antibiotics.(25)

\section{Complications}

Children in whom the diagnosis and treatment were delayed and with infections by more virulent pathogens such as MRSA and PantonValentine leukocidin.(25) producing strains of Staphylococcus aureus are at higher risk for developing complications. Early complications include abscess formation, pyomyositis, necrotizing fasciitis, septicemia and septic shock, deep vein thrombosis and pulmonary embolism. Complications need to be treated with at least four to six weeks of intravenous antibiotics.(26)

Long term complications include damage to growth plate of long bones leading to leg deformity and length discrepancy, avascular necrosis of femoral head, chronic and recurrent osteomyelitis, pathological fractures and growth failure.

\section{References}

1. Akinkugbe O, Stewart C, McKenna C. Presentation and Investigation of Pediatric Bone and Joint Infections in the Pediatric Emergency Department. Pediatr Emerg Care. 2019 Oct;35(10):700-704. doi: 10.1097/ PEC.0000000000001431.

2. Iliadis AD, Ramachandran M. Paediatric bone and joint infection. EFORT Open Rev. 2017;2(1):7-12. Published 2017 Mar 13. doi:10.1302/2058-5241.2.160027

3. Pääkkönen M, Kallio MJ, Lankinen P, Peltola $\mathrm{H}$, Kallio PE. Preceding trauma in childhood hematogenous bone and joint infections. J Pediatr Orthop B. 2014 Mar;23(2):196-9. doi: 10.1097/BPB.0000000000000006.
4. Arnold J.C., Bradley J.S. Osteoarticular infections in children. Infect. Dis. Clin. N. Am. 2015;29:557-574. doi: 10.1016/j. idc.2015.05.012.

5. Dartnell J, Ramachandran M, Katchburian M. Haematogenous acute and subacute paediatric osteomyelitis: A systematic review of the literature. J Bone Joint Surg [Br] 2012;94B:584-595.

6. Le Saux N. Diagnosis and management of acute osteoarticular infections in children. Paediatr Child Health. 2018;23(5):336-343. doi:10.1093/pch/pxy049

7. Butbul-Aviel Y, Koren A, Halevy R, Sakran W. Procalcitonin as a diagnostic aid in osteomyelitis and septic arthritis. Pediatr Emerg Care 2005;21(12):828-32.

8. Thomsen I., Creech C.B. Advances in the diagnosis and management of pediatric osteomyelitis. Curr. Infect. Dis. Rep. 2011;13:451-460. doi: 10.1007/s11908-0110202-Z

9. Williams DJ, Deis JN, Tardy J, Creech CB. Culture-negative osteoarticular infections in the era of community-associated methicillinresistant Staphylococcus aureus. Pediatr Infect Dis J 2011;30(6):523-5.

10. Russell CD, Ramaesh R, Kalima P, Murray A, Gaston MS. Microbiological characteristics of acute osteoarticular infections in children. $\mathrm{J}$ Med Microbiol 2015;64(Pt 4):446-53.

11. Ceroni D, Kampouroglou G, Valaikaite R, Anderson della Llana R, Salvo D. Osteoarticular infections in young children: What has changed over the last years? Swiss Med Wkly 2014;144:w13971.

12. Slinger R, Moldovan I, Bowes J, Chan F. Polymerase chain reaction detection of Kingella kingae in children with culture- negative septic arthritis in eastern Ontario. Paediatr Child Health 2016;21(2):79-82.

13. Yagupsky P. Letter to the editor: Another look; Is there a flaw to current hip septic arthritis diagnostic algorithms?Clin Orthop Relat Res 2014;472(1):383-4. 
14. Saavedra-Lozano J, Falup-Pecurariu O, Faust SN, Girschick H, Hartwig N, Kaplan S, et al. Bone and Joint Infections. Pediatr Infect Dis J. 2017 Aug; 36(8):788-799. doi: 10.1097/ INF.0000000000001635.

15. Lima AL, Oliveira PR, Carvalho VC, Cimerman $\mathrm{S}$, Savio E; et al. Recommendations for the treatment of osteomyelitis. Braz J Infect Dis. 2014 Sep-Oct;18(5):526-34. doi: 10.1016/j. bjid.2013.12.005. Epub 2014 Apr 1.

16. Alvares PA, Mimica MJ. Osteoarticular infections in pediatrics. J Pediatr (Rio J). 2020 Mar - Apr;96 Suppl 1:58-64. doi: 10.1016/j. jped.2019.10.005. Epub 2019 Nov 26.

17. Copley LA, Kinsler MA, Gheen T, et al. The impact of evidence-based clinical practice guidelines applied by a multidisciplinary team for the care of children with osteomyelitis. J Bone Joint Surg [Am] 2013;95-A:686-693.

18. Faust S.N., Clark J., Pallett A., Clarke N.M. Managing bone and joint infection in children. Arch. Dis. Child. 2012;97:545-553. doi: 10.1136/archdischild-2011-301089.

19. Harik N.S., Smeltzer M.S. Management of acute hematogenous osteomyelitis in children. Expert Rev. Antinfect. Ther. 2010;8:175-181. doi: 10.1586/eri.09.130.

20. Peltola H., Pääkkönen M., Kallio P., Kallio M.J. OM-SA Study Group. Clindamycin vs. first-generation cephalosporins for acute osteoarticular infections of childhood-A prospective quasi-randomized controlled trial. Clin. Microbiol. Infect. 2012;18:582-589. doi: 10.1111/j.1469-0691.2011.03643.x.

21. Peltola H., Pääkkönen M. Acute osteomyelitis in children. N. Engl. J. Med. 2014;370:352360. doi: 10.1056/NEJMra1213956.
22. Castellazzi L, Mantero M, Esposito S. Update on the Management of Pediatric Acute Osteomyelitis and Septic Arthritis. Int J Mol Sci. 2016;17(6):855. Published 2016 Jun 1. doi:10.3390/ijms17060855

23. Zhorne D, Bradford KK, Jhaveri R. Review of Pediatric Osteoarticular Infections. Reviews on Recent Clinical Trials (2017) 12: 260. https:// doi.org/10.2174/1574887112666170828120 040

24. Peltola H., Pääkkönen M., Kallio P., Kallio M.J. Osteomyelitis-Septic Arthritis (OM-SA) Study Group. Prospective, randomized trial of 10 days versus 30 days of antimicrobial treatment, including a short-term course of parenteral therapy, for childhood septic arthritis. Clin. Infect. Dis. 2009;48:1201-1210. doi: $10.1086 / 597582$.

25. Bruce CE, RowlandDJ, Katchburian M, Dartnell J, Robb JE. British Society for Children's Orthopaedic Surgery. The management of acute bone and joint infection in childhood - a guide to good practice. http://bscos.org.uk/resources/ Downloads/Blue-Book-Infection.pdf(date last accessed 05 December 2016).

26. Krogstad P. Osteomyelitis. In: Feigin RD, Cherry JD, Demmler-Harrison GD, Kaplan SL, editors. Textbook of Pediatric Infectious Diseases. 6th Edition. PA, USA: Saunders Elsevier; 2009. pp. 725-742.

27. Ilharreborde B. Sequelae of pediatric osteoarticular infection. Orthop. Traumatol. Surg. Res. 2015;101(Suppl. 1):S129-S137. doi: 10.1016/j.otsr.2014.07.029.

28. Pendleton A, Kocher MS. Methicillinresistant staphylococcus aureus bone and joint infections in children. J Am Acad Orthop Surg. 2015;23(1):29-37. doi:10.5435/ JAAOS-23-01-29 